\title{
Prevalence of Listeria monocytogenes in ready-to-eat seafood marketed in Thessaloniki ( Northern Greece)
}

\author{
N. Soultos, E. Iossifidou, Z. Tzikas, D. Sergelidis, Th. Lazou, G. Drakopoulos and I. Konstantelis
}

Department of Hygiene and Technology of Foods of Animal Origin, Laboratory of Hygiene of Foods of Animal Origin, School of Veterinary Medicine, Faculty of Health Sciences, Aristotle University of Thessaloniki, Thessaloniki, Greece.

Corresponding author: N. Soultos, e-mail: soultos@vet.auth.gr, El: ehygfood@vet.auth.gr, ZT: ztzikas@gmail.com,

DS: dsergkel@vet.auth.gr, ThL: thomilazou@yahoo.gr, GD: gdrakopoulo@yahoo.gr, IK: johnkon76@gmail.com Received: 15-09-2014, Revised: 25-10-2014, Accepted: 27-10-2014, Published online: 27-11-2014

doi: 10.14202/vetworld.2014.1004-1009. How to cite this article: Soultos N, Iossifidou E, Tzikas Z, Sergelidis D, Lazou Th, Drakopoulos G, Konstantelis I (2014) Prevalence of Listeria monocytogenes in ready-to-eat seafood marketed in Thessaloniki (Northern Greece), Veterinary World, 7(11): 1004-1009.

\begin{abstract}
Aim: In the current study, a contribution to the knowledge on the prevalence and level of contamination of Listeria monocytogenes in ready-to-eat (RTE) seafood marketed in Thessaloniki (Northern Greece) was provided; the serovar identity of the L. monocytogenes isolates was also determined.

Materials and Methods: A total of 132 RTE seafood samples consisting of 74 smoked fish products, 18 salted fish products, 16 dried fish products, 9 raw marinated fish products, 10 cooked marinated cephalopods and 5 surimi crab stick products were analyzed. L. monocytogenes were isolated and enumerated based on ISO 11290-1/A1 and ISO 11290-2/A1 protocols, respectively, and identified using a multiplex polymerase chain reaction (PCR) system utilizing genus and species specific primers. For the identification of serotypes a second multiplex PCR assay was used which clusters L. monocytogenes strains into four major serogroups.

Results: Of the samples examined, 11 (8.3\%) proved positive for Listeria spp. with 8 (6.1\%) yielding L. monocytogenes. Only in one sample of smoked mackerel the level of L. monocytogenes exceeded the legal safety limit of $100 \mathrm{cfu} / \mathrm{g}$ set out in Commission Regulation (EC) No. 1441/2007. Serotyping showed higher percentages of isolates belonging to PCR serogroup 3:1/2b, 3b, 7 (46.7\%) and serogroup 1:1/2a, 3a (40\%) followed by serogroup 4:4b, 4d, 4e (13.3\%).

Conclusion: This study demonstrated that L. monocytogenes can be isolated from processed RTE seafood products at retail in Thessaloniki (Northern Greece) in low concentrations. However, the presence of this human pathogen in RTE seafood should not be overlooked, but it should be considered as having significance public health implications, particularly among the persons who are at greater risk. Therefore, RTE seafood should be produced under appropriate hygienic and technological conditions since the product does not undergo any treatment before consumption.
\end{abstract}

Keywords: level, Listeria monocytogenes, Northern Greece, prevalence, ready-to-eat seafood, serotyping.

\section{I ntroduction}

Listeria monocytogenes, the causative agent of listeriosis, is a well-known foodborne pathogen which continues to be of major concern for food industry, public health authorities and consumers. Listeriosis represents a severe public health problem because $L$. monocytogenes can produce life-threatening infections with high mortality rate, especially among susceptible populations. In some risky groups i.e. the young, the old, the pregnant women and the immunocopromised individuals, the so called "YOPI" [1], the lethality is as high as 20-30\% [2].

Many outbreaks as well as isolated cases of listeriosis occur worldwide. Although various foods can serve as sources of food-borne listeriosis, typically, the disease is associated with the consumption of prepared RTE foods that have extended shelf life and are stored in chilled environment [3]. This category of food does not undergo any treatment to ensure its safety before consumption and therefore risk of food-borne listeriosis must be considered if the pathogen is present in

Copyright: The authors. This article is an open access article licensed under the terms of the Creative Commons Attributin License (http:// creative commons.org/licenses/by/2.0) which permits unrestricted use, distribution and reproduction in any medium, provided the work is properly cited. the food. RTE seafood products, in particular, have been sources of infection with $L$. monocytogenes and lightly preserved fish products are classified as high risk merchandise [4]. Epidemiological evidence has suggested that listeriosis has been caused by smoked mussels [5], cold-smoked rainbow trout [6] and vacuum-packed gravad trout [7].

In the Community Summary Report [8] the highest frequencies of positive samples in RTE foods were found in fish products in 2012; 10.3\% for fish products and clearly lower $2.1 \%$ for meat products and 0.47 for cheese products. In European Counties, the number of infections from $L$. monocytogenes showed an increasing trend over the 5 year period 2008-2012, with 1642 confirmed human cases, 198 deaths (case fatality rate $17.8 \%$ ) and annual incidence 0.41 cases per 100,000 inhabitants in 2012 [8]. The observed increasing incidence of listeriosis cases in humans within European Union could be attributed mainly to the extended consumption of ready-to-eat (RTE) products $[8,9]$ and the increase of vulnerable population, especially the elderly individuals $[8,10,11]$.

In Greece, listeriosis is not common and only 11 confirmed cases were reported in 2012 [8]; however, 
this number is likely an underestimate of the actual number of cases since many cases of food-borne illness are not reported to public health officials [12]. Although L. monocytogenes has been detected from different types of foods in Greece, there is a lack of information on the occurrence of $L$. monocytogenes in RTE seafood products.

Thus, the purpose of the present study was to generate information on the prevalence and the level of contamination of this pathogen in RTE seafood marketed in Thessaloniki (Northern Greece); the serovar identity of the $L$. monocytogenes isolates was also determined.

\section{Materials and Methods}

\section{Sample collection}

A total of 132 RTE seafood samples consisting of 74 smoked fish products, 18 salted fish products, 16 dried fish products, 9 raw marinated fish products, 10 cooked marinated cephalopods and 5 surimi crab stick products (Table-1) were analyzed. All samples were packaged (sliced or unsliced), with packaging sizes ranging from 100 to $250 \mathrm{~g}$ and extended shelflife $>20$ days and purchased at retail from five different supermarket chains in Thessaloniki (Northern Greece). Immediately following purchase, samples were transported to the laboratory inside a portable ice-chest and examined within $1 \mathrm{~h}$ of arrival.

\section{Detection and enumeration of $\mathbf{L}$. monocytogenes}

Procedures based on ISO, 11290-1/A1 [13] and ISO 11290-2/A1 [14] were used to detect and enumerate L. monocytogenes, respectively, in seafood samples. Briefly, $25 \mathrm{~g}$ of each sample were added to $225 \mathrm{ml}$ of half Fraser broth base (without supplements) and homogenized in a stomacher 400 Labblender (Seward Medical, London, UK) for $2 \mathrm{~min}$. The suspensions were incubated at $20^{\circ} \mathrm{C}$ for $1 \mathrm{~h}$, in order to recover stressed microorganisms. For enumeration of L. monocytogenes, $0.1 \mathrm{ml}$ of each suspension was spread over Agar Listeria Ottaviani Agosti

Table-1: Prevalence of Listeria spp. and L. monocytogenes in RTE seafood.

\begin{tabular}{lccc}
\hline Product type & $\begin{array}{c}\text { Number } \\
\text { of } \\
\text { samples }\end{array}$ & \multicolumn{2}{c}{$\begin{array}{c}\text { Number of positive } \\
\text { samples (\% ) }\end{array}$} \\
\cline { 3 - 4 } & & $\begin{array}{c}\text { Listeria } \\
\text { spp. }\end{array}$ & L. monocytogenes \\
\hline Smoked fish & 76 & $3(3.9)$ & $3(3.9)$ \\
$\begin{array}{l}\text { Dried fish } \\
\text { Salted fish }\end{array}$ & 16 & $2(12.5)$ & $2(12.5)$ \\
Raw marinated & 18 & $3(16.7)$ & $2(11.1)$ \\
fish & 9 & $3(33.3)$ & $1(11.1)$ \\
$\begin{array}{l}\text { Cooked } \\
\text { marinated }\end{array}$ & 8 & $0(-)$ & $0(-)$ \\
cephalopods & & & \\
$\begin{array}{l}\text { Surimi crab } \\
\text { stick }\end{array}$ & 5 & $0(-)$ & $0(-)$ \\
Total & 132 & $11(8.34)$ & $8(6.1)$ \\
\hline
\end{tabular}

L. monocytogenes=Listeria monocytogenes, $\mathrm{RTE}=$ Ready-to-eat
(ALOA) (Biolife, Milan-Italy) and incubated at $37^{\circ} \mathrm{C}$ for 24-48 h. For the detection of $L$. monocytogenes, the prepared suspension was supplemented by Fraser half selective supplement (primary enrichment) and incubated $\left(24 \mathrm{~h}, 30^{\circ} \mathrm{C}\right)$. Following this, a secondary enrichment was prepared by inoculating an aliquot $(0.1 \mathrm{ml})$ of the primary culture into $10 \mathrm{ml}$ Fraser broth $\left(48 \mathrm{~h}, 30^{\circ} \mathrm{C}\right)$. Afterward, a loopful $(10 \mu \mathrm{l})$ of the primary and secondary enriched cultures were streaked onto ALOA (Biolife, Milan-Italy) and Oxford agar and examined after 24 and $48 \mathrm{~h}\left(37^{\circ} \mathrm{C}\right)$. Five suspect Listeria spp. colonies from each plate were streaked to purity on tryptone soya agar with yeast extract (24 h, $37^{\circ} \mathrm{C}$ ).

\section{I dentification}

For the identification of Listeria spp., pure cultures in tryptone soya agar were submitted to a multiplex polymerase chain reaction (PCR) procedure, according to Lawrence and Gilmour [15], using the conditions described by authors. This assay uses a combination of genus-and-species specific primers (U1, U2, LI1, LM1 and LM) and gives three results: A band indicative of bacterial DNA (U1, U2), Listeria spp. (LI1, U1) and L. monocytogenes (LM1, LM2).

\section{Serotyping}

Strains identified as L. monocytogenes were further serotyped using a second multiplex PCR assay, as described by Doumith et al. [16]. This system uses four set of primers specific for L. monocytogenes, (Imo737, Imo1118, ORF2819, ORF2110) and an addition set of primers (prs) specific for Listeria spp. Applying this method, L. monocytogenes strains are classified in four PCR groups of serotypes (Group 1: Corresponding to conventional serotypes $1 / 2 a$, 3a; Group 2: Corresponding to conventional serotypes 1/2c, 3c; Group 3: Corresponding to conventional serotypes 1/2b, 3b, 7; and Group 4: Corresponding to conventional serotype serotypes $4 \mathrm{~b}, 4 \mathrm{~d}, 4 \mathrm{e}$ ).

Appropriate positive and negative controls were included in all assays.

\section{Results}

In the present study, a total of 132 RTE seafood samples were analyzed. Table- 1 lists the various retail RTE seafood products that were analyzed, the number of samples of each product tested and the values of Listeria spp. and L. monocytogenes contamination. Of the samples examined, 11 (8.3\%) proved positive for Listeria spp. With 8 (6.1\%) yielding L. monocytogenes. The pathogen was not detected $(<1$ organism in $25 \mathrm{~g}$ ) from the 8 cooked marinated cephalopods and the 5 surimi crab sticks tested samples.

The level of $L$. monocytogenes in the 7 out of 8 positive samples did not exceed the legal safety limit of $100 \mathrm{cfu} / \mathrm{g}$ set out in Commission Regulation (EC) No. 1441/2007 on microbiological criteria for foodstuffs [17]. Only in one sample of smoked mackerel higher levels of contamination (110 cfu/g) were found. 
Altogether, 15 isolates of $L$. monocytogenes were obtained from the 8 positive RTE seafood samples; of which 8 were isolated from the 3 smoked fish, 3 from 2 salted fish, 3 from 2 dried fish and 1 from 1 raw marinated fish. The $15 \mathrm{~L}$. monocytogenes isolates were classified in three serovar groups (Table-2). Most isolates tested 7 (46.7\%) belonged to serogroup 3 (1/2b, 3b, 7), 6 (40\%) were identified as serogroup 1 $(1 / 2 a, 3 a)$ and only 2 (13.3\%) were identified as serogroup 4 (4b, 4d, 4e). Multiple serogroups were not observed in any of the samples tested.

\section{Discussion}

The general occurrence of $L$. monocytogenes in various RTE food groups, including RTE seafood products and in various food processing environments is well documented in many countries, and seem to enhance the general view that $L$. monocytogenes is an ubiquitous bacterial pathogen. The microorganism because of its ubiquity in nature may be introduced into food-processing environments and ultimately may result in the contamination of food products [18]. The association of $L$. monocytogenes with RTE seafood is most likely due to environmental contamination occurring during processing. The raw fish material as well as food handlers may be sources of L. monocytogenes introducing it into the factory environment [19]; however product contamination is often contamination during processing rather than by survivors from the raw material [20]. L. monocytogenes is capable of colonizing food processing environments and readily forms biofilms allowing the pathogen to adhere and survive on different surfaces of food-processing settings [21,22]. Pieces of biofilms incorporating $L$. monocytogenes may be dislodged either continuously or occasionally and contaminate food products during processing.

Unlike some other food-borne pathogens, the organism has the ability to survive and grow in stress conditions such as refrigeration temperatures, high salt concentrations, low concentration of oxygen, low water activity as well as low $\mathrm{pH}$ values $[2,23,24]$. These properties of the pathogen appear to be the main cause of its occurrence in RTE seafood products with extended shelf lives.

The results of the current study demonstrate that $8.3 \%$ of the retail RTE seafood samples tested were contaminated with Listeria spp. and 6.1\% were

Table-2: Distribution of the serotypes in the 15 strains of L. monocytogenes isolated from RTE seafood.

\begin{tabular}{lcccc}
\hline $\begin{array}{l}\text { Serogroup } \\
\text { (serotypes) }\end{array}$ & \multicolumn{4}{c}{ Number of samples (isolates) } \\
\cline { 2 - 5 } & $\begin{array}{c}\text { Smoked } \\
\text { fish }\end{array}$ & $\begin{array}{c}\text { Salted } \\
\text { fish }\end{array}$ & $\begin{array}{c}\text { Dried } \\
\text { fish }\end{array}$ & $\begin{array}{c}\text { Raw } \\
\text { marinated fish }\end{array}$ \\
\hline $1(1 / 2 a, 3 a)$ & $2(6)$ & & & \\
$3(1 / 2 b, 3 b, 7)$ & $1(2)$ & $2(3)$ & $1(2)$ & \\
$4(4 b, 4 d, 4 e)$ & & & $1(1)$ & $1(1)$ \\
\hline
\end{tabular}

L. monocytogenes=Listeria monocytogenes, RTE $=$ Ready-to-eat contaminated with $L$. monocytogenes. The incidence of L. monocytogenes observed in our study is in accordance with published data in Malaysia, which reported the presence of the pathogen in $6.7 \%$ of RTE seafood-based products [25]. Previous studies, carried out in other countries, revealed prevalence of $L$. monocytogenes in RTE seafood products ranging from 1.4\% to $66.7 \%$ [9]. High L. monocytogenes isolation rates $34.1 \%, 27.8 \%$ and $21.6 \%$ were reported in smoked fish products obtained from retail market in Italy [26], Belgium [27] and Ireland [28], respectively. Two recent studies carried out in Israel by Vasilev et al. [29] and in Iran by Fallah et al. [30] revealed approximately similar rate of $L$. monocytogenes contamination $15 \%$ and $14.5 \%$ in RTE seafood products, respectively. In Italy, in a survey of the prevalence of L. monocytogenes in RTE foods, smoked fish were found to harbor the pathogen at a rate $12 \%$ [31]. Similar occurrence (12\%) was also observed by Lambertz et al. [32] in a study conducted in RTE fish products at retail markets in Sweden. However, much lower incidences of L. monocytogenes have been found in smoked seafood (4.31\%) and seafood salads (1.4\%) samples from retail markets in the United States [33].

Failure to detect $L$. monocytogenes in certain types of RTE seafood products has also been documented. In the current study, none of the 8 cooked marinated cephalopods and the 5 surimi crab sticks tested samples were contaminated with the pathogen. This pathogen was not isolated from raw marinated products [31] and smoked salmon [34] marketed in Italy or in any of the 125 surimi tested samples in a survey undertaken in Spain [35]; the microorganism was not detected in domestic or imported dried seafood (shrimps, squids) and smoked mussels in a survey conducted in Korea, as well [36]. The discrepancies in the prevalence of $L$. monocytogenes among different studies and countries may be due to type of seafood sample, differences in food-processing environment, source of the samples (retail level and factories), sampling season, isolation method, human activity etc.

The significance of listeriosis with regard to level infectious dose and serotype of $L$. monocytogenes is well known. Currently, there is insufficient data for the dose-response relationship to be determined, however, it has been established that only exposure to high levels of L. monocytogenes (>1000 cfu/g) causes listeriosis [37]. According to International Commission on Microbiological Specification of Foods [37,38], foods in which $L$. monocytogenes levels do not exceed 100 $\mathrm{cfu} / \mathrm{g}$ at the time of consumption are acceptable for a healthy human population. Therefore, the European Commission Regulations (EC) No. 2073/2005 [39] and No. 1441/2007 [17] on microbiological criteria for foodstuffs established a limit of $100 \mathrm{cfu} / \mathrm{g}$ for RTE foods unable to support the growth of L. monocytogenes throughout their shelf-life. For RTE foods that are able to support the growth of bacterium, L. monocytogenes is required to be absent in $25 \mathrm{~g}$ at the time 
leaving the production plant, if the producer is not able to demonstrate that the product will not exceed the limit of $100 \mathrm{cfu} / \mathrm{g}$ throughout its shelf-life.

Data regarding levels of $L$. monocytogenes in RTE seafood are very limit, since, in previously published surveys, most often only prevalence rates have been reported. In the present study, the microbial load of L. monocytogenes in the 7 out of the 8 positive samples was $<100 \mathrm{cfu} / \mathrm{g}$, in conformity with the food safety criteria provided by the Commission Regulation (EC) No. 1441/2007 for RTE foods [17] able to support the growth of the pathogen. Only in one sample of smoked mackerel were found higher levels of contamination (110 cfu/g).

These results are in agreement with those reported in previous studies carried out in Spain [35], in Sweden [32] and in Belgium [27]; the observed percentages of unsafe samples were very low $(\approx 0.4 \%)$. However, higher concentrations of the pathogen have been reported for certain types of RTE seafood products. Contamination levels $>100 \mathrm{cfu} / \mathrm{g}$ were reported for smoked and gravid fish, smoked seafood and seafood salads [30,33,40]. Dominguez et al. [41], in a survey carried out in Spain, reported that of the 38 positive retail smoked fish samples, 18 contained 100-1000 cfu/g L. monocytogenes and two samples (vacuum-packaged cold-smoked salmon and rainbow trout) contained the organism at levels exceeding $1000 \mathrm{cfu} / \mathrm{g}$. In the European Union, the highest proportion of non-compliant units were observed in RTE fishery products, at levels of $8.0 \%$ and $0.5 \%$ in single samples, at processing and at retail, respectively, in 2012 [8].

Serotyping of $L$. monocytogenes has been widely used for epidemiological monitoring and may have value as a virulence screening test. Furthermore, for the food industry, where the presence of the pathogen is a big concern, tracing contamination strains within the food chain, and the plant environment is of primary importance. L. monocytogenes is made up of 13 serotypes showing varied virulence potential. It has been confirmed through studies that only four of these serovars (1/2a, 1/2b, 1/2c and specifically $4 \mathrm{~b})$ account for the majority of foodborne listeriosis outbreaks, providing additional evidence that certain serotypes have greater potential to cause illness $[2,8,42,43]$. Other serotypes (i.e. 3a, 3b, 3c, 4a, 4c, 4e, 4d and 7) are very infrequent in food and rarely responsible for human $L$. monocytogenes infections $[16,44]$.

Serotyping in the present study, using a rapid and practical multiplex PCR assay described by Doumith et al. [16], showed higher percentages of isolates belonging to PCR serogroup 3 (7 isolates, 46.7\%) and serogroup 1 (6 isolates, 40\%) followed by serogroup 4 (2 isolates, 13.3\%). L. monocytogenes belonging to molecular serogroup 3 , containing serotypes $1 / 2 b$, $3 b$ and 7, could be isolated from most RTE seafood categories (smoked fish, salted fish and dried fish). Two isolates of serogroup 4, corresponding to serotypes
$4 \mathrm{~b}, 4 \mathrm{~d}$ and $4 \mathrm{e}$, were detected from two samples of dried fish and raw marinated fish respectively, while all isolates of serogroup 1 that includes serotypes 1/2a and 3a were found in two samples of smoked fish (Table-2). Simultaneous existence of isolates belonging to different serogroups in one single seafood product was not observed.

A disadvantage of Doumith's multiplex PCR assay used for serotyping in this study is that it is less discriminating than agglutination method [45]. This assay separates $L$. monocytogenes isolates into four distinct molecular serogroups, in which each molecular serogroup contains one of the four principal serotypes (1/2a, 1/2b, 1/2c and $4 \mathrm{~b})$ associated with Hunan listeriosis [16]. As it was reported by Doumith et al. [16], multiplex PCR profiles do not distinguish, within the species of $L$. monocytogenes, serotype $1 / 2 \mathrm{a}$ from $3 \mathrm{a}$, serotype $1 / 2 \mathrm{~b}$ from $3 \mathrm{~b}$ and 7 and serotype $4 \mathrm{~b}$ from $4 \mathrm{~d}$ and $4 \mathrm{e}$. However, this drawback would not decrease the efficiency of the multiplex PCR assay in long-term epidemiological studies [44] as this method may be used as a first level in discriminating of $L$. monocytogenes strains of different origin. Indeed, serotypes 3a, 3b, 7, 4d and 4e are relatively rare in foods and particularly rarely reported as implicated in human listeriosis $[16,44]$. In contrast, previous studies from different countries revealed that serotypes $1 / 2 \mathrm{a}, 1 / 2 \mathrm{~b}$ and $4 \mathrm{~b}$ tend to be predominant in seafood products and production plants $[29,30,31,46-49]$. Thus, in this study, the isolated strains from RTE seafood samples assigned into serogroups $1(1 / 2 a, 3 a), 3(1 / 2 b, 3 b, 7)$ and $4(4 b$, $4 \mathrm{~d}, 4 \mathrm{e}$ ) may be presumptively serotypes $1 / 2 \mathrm{a}, 1 / 2 \mathrm{~b}$ and $4 \mathrm{~b}$, respectively. Specifically, it has been reported that serotype 1/2a was prevalent in RTE seafood in Italy and Estonia [31,47]; serotype 4b was predominant in seafood products in Israel and China $[29,49]$ and serotype $1 / 2 \mathrm{~b}$ was the dominant serotype in Turkish seafood products [48]. Furthermore, a survey conducted in Iran indicated that serotypes 1/2a and 4b were the dominant serotypes in seafood products and environmental samples during warm and cold seasons, respectively [30]. In addition, a high percentage rate of serogroup $1(1 / 2 a, 3 a)$ has been found in RTE seafood products in Malaysia [50].

\section{Conclusion}

In conclusion, this study demonstrated that L. monocytogenes were isolated from processed RTE seafood products at retail in Thessaloniki (Northern Greece) in low concentrations. Nevertheless, considering that the bacterium has the potential to grow well at refrigerated temperatures and in high salt matrixes such as seafood, its presence in these products should not be overlooked. Therefore, more attention should be focused by the consumers on the product's shelf life and the cold chain.

Due to the ubiquitous nature of $L$. monocytogenes it is extremely difficult to produce RTE seafood 
products without sporadic occurrence of the bacterium in low levels. Therefore, it is of great importance for the producer to introduce effective control procedures throughout the production of RTE seafood in order to avoid colonization of the processing environment and subsequent spread to the finished product. This should be done by implementation of a comprehensive control system involving a combination of strategies that are compatible with hazard analysis critical control point, good hygiene practices and good manufacturing practices; the application of these measures will help to reduce the presence of the pathogen in the factory and consequently assure the microbiological safety and quality of the finished product.

\section{Authors' Contributions}

NS designed the plan of work and wrote the manuscript. EI and ZT collected the relevant samples and assisted in writing the manuscript. DS, TL, GD and IK carried out the laboratory work. All the authors have read and approved the manuscript. NS and ZT revised the manuscript. All authors read and approved the final manuscript.

\section{Acknowledgments}

This study was financially supported by the Greek Military Land Forces - Medical Service.

\section{Competing I nterests} interests.

The authors declare that they have no competing

\section{References}

1. de Cesare, A., Manfreda, G., Macri, M. and Cantoni, C. (2006) Application of automated ribotyping to support the evaluation of the $L$. monocytogenes source in a taleggio producing plant and to predict the risk human health linked to the accidental sale of contaminated cheese. Arch. Vet. Ital., 57: 231-240.

2. Swaminathan, B., Cabanes, D., Zhang, W. and Cossart, P. (2007) L. monocytogenes. In: Doyle, M.P. and Beuchat, L.R. editors. Food Microbiology: Fundamentals and Frontiers. ASM Press, Washington, DC. p457-491.

3. EUFIC (The European Food Information Council). (2006) Some animal diseases and their possible impact on food safety. Available from: http://www.eufic.org/article/en/ food-safety-quality/animal-health/expid/review-animal-diseases. Accessed on 09-07-2014.

4. Rocourt, J., Jacquet, C. and Reilly, A. (2000) Epidemiology of human listeriosis and seafoods. Int. J. Food Microbiol., 62: 197-209.

5. Brett, M.S., Short, P. and McLauchlin, J. (1998) A small outbreak of listeriosis associated with smoked mussels. Int. J. Food Microbiol., 43(3): 223-229.

6. Miettinen, M.K., Siitonen, A., Heiskanen, P., Haajanen, H., Björkroth, K.J. and Korkeala, H.J. (1999) Molecular epidemiology of an outbreak of febrile gastroenteritis caused by Listeria monocytogenes in cold-smoked rainbow trout. J. Clin. Microbiol., 37(7): 2358-2360.

7. Tham, W., Ericsson, H., Lonvarevic, S., Unnerstad, H. and Danielsson-Tham, M.L. (2000) Lessons from an outbreak of listeriosis related to vacuum-packed gravid and coldsmoked fish. Int. J. Food Microbiol., 62(3): 173-175.

8. EFSA (European Food Safety Authority). (2014) The European Union summary report on trends and sources of zoonoses, zoonotic agents and food-borne outbreaks in 2012. Eur. Food Saf. Authority J., 12(2): 3547.

9. Lianou, A. and Sofos, J.N. (2007) A review of the incidence and transmission of Listeria monocytogenes in ready-to-eat products in retail and food service environments. J. Food Protect., 70(9): 2172-2198.

10. Goulet, V., Hedberg, C., Le Monnier, A. and de Valk, H. (2008) Increasing incidence of listeriosis in France and other European countries. Emerg. Infect. Dis., 14(5): 734-740.

11. Garrido, V., Vitas, A.I., García-Jalón, I., Torroba, L. and Navascués, A. (2012) Epidemiology of invasive listeriosis in clinical cases in Navara (Spain): comparison between 1995-2005 and 2006-2011. In: Romano, A. and Giordano, C.F. editors. Listeria Infections: Epidemiology, Pathogenesis and Treatment. Nova Science Publishers, New York. p141-154.

12. Tirado, C. and Schmidt, K. (2001) WHO surveillance programme for control of foodborne infections and intoxications: Preliminary results and trends across greater Europe. J. Infect., 43: 80-84.

13. ISO. (2005a) Horizontal method for the detection and enumeration of Listeria monocytogenes. In Part 1: Detection method. Amendment 1: Modification of the isolation media and haemolysis test, and inclusion of precision data. International Organization for Standarization, Geneva, International Standard ISO 11290-1:1996/Amd 1:2005.

14. ISO (2005b) Horizontal method for the detection and enumeration of Listeria monocytogenes. In Part 2: Enumeration method. Amendment 1: Modification of the enumeration medium. International Organization for Standarization, Geneva, International Standard ISO 11290-2:1998/Amd 1:2005.

15. Lawrence, L.M. and Gilmour, A. (1994) Incidence of Listeria spp. and $L$. monocytogenes in a poultry processing environment and in poultry products and their rapid confirmation by multiplex PCR. Appl. Environ. Microbiol., 60: 4600-4604.

16. Doumith, M., Buchrieser, C., Glaser, P., Jacquet, C. and Martin, P. (2004) Differentiation of the major L. monocytogenes serovars by multiplex PCR. J. Clin. Microbiol., 42: 3819-3822.

17. The Commission of the European Communities. (2007) Commission regulation (EC) No.1441/2007, amending regulation (EC) No.2073/2005 on microbiological criteria for foodstuffs. Official J. Eur. Union, L322: 12-29.

18. Cartwright, E.J., Jackson, K.A., Johnson, S.D., Graves, L.M., Silk, B.J. and Mahon, B.E. (2013) Listeriosis outbreaks and associated food vehicles, United States, 19982008. Emerg. Infecti. Dis., 19: 1-9.

19. Cruz, C.D., Silvestre, F.A., Kinoshita, E.M., Landgraf, M., Franco, B.D.G.M. and Destro, M.T. (2008) Epidemiological survey of Listeria monocytogenes in a gravlax salmon processing line. Braz. J. Microbiol., 39(2): 375-383.

20. Gram, L. (2004) How to meet an FSO - Control of Listeria monocytogenes in the smoked fish industry. Mitt. Lebensm Hyg., 95: 59-67.

21. Beresford, M.R., Andrew, P.W. and Shama, G. (2001) Listeria monocytogenes adheres to many materials found in food-processing environments. J. Appl. Bacteriol., 90: 1000-1005.

22. Chaturongkasumrit, Y., Takahashi, H., Keeratipibul, S., Kuda, T. and Kimura, B. (2011) The effect of polyurethane belt surface roughness on Listeria monocytogenes biofilm formation and its cleaning efficiency. Food Control, 22: 1893-1899.

23. Warriner, K. and Namvar, A. (2009) What is the hysteria with Listeria? Trends Food Sci. Technol., 20(6-7): 245-254.

24. Todd, E.C.D. and Notermans, S. (2011) Surveillance of listeriosis and its causative pathogen, Listeria monocytogenes. Food Control, 22: 1484-1490.

25. Jamali, H., Chai, L.C. and Thong, K.L. (2013) Detection and isolation of Listeria spp. and Listeria monocytogenes 
in ready-to-eat foods with various selective culture media. Food Control, 32: 19-24.

26. Di Pinto, A., Novello, L., Montemurro, F., Bonerba, E. and Tantillo, G. (2010) Occurrence of Listeria monocytogenes in ready-to-eat foods from supermarkets in Southern Italy. New Microbiol., 33(3): 249-252.

27. Uyttendaele, M., Busschaert, P., Valero, A., Geeraerd, A.H., Vermeulen, A., Jacxsens, L., Goh, K.K., De Loy, A., Van Impe, J.F. and Devlieghere, F. (2009) Prevalence and challenge tests of Listeria monocytogenes in Belgian produced and retailed mayonnaise-based deli-salads, cooked meat products and smoked fish between 2005 and 2007. Int. J. Food Microbiol., 133(1-2): 94-104.

28. Dass, S.C., Cummins, E.J. and Abu-Ghannam, N. (2011) Prevalence and typing of Listeria monocytogenes strains in retail vacuum-packed cold-smoked salmon in the Republic of Ireland. J. Food Saf., 31: 21-27.

29. Vasilev, V., Japheth, R., Breuer, R., Andorn, N., Ben Abraham, R., Yoni, Y., Valinsky, L. and Agmon, V. (2010) A survey of Listeria monocytogenes strains, isolated from ready-to-eat foods in Israel over a period of 10 years, 1998-2007. Food Control, 21: 1179-1181.

30. Fallah, A.A., Saei-Dehkordi, S.S. and Mahzounieh, M. (2013) Occurrence and antibiotic resistance profiles of Listeria monocytogenes isolated from seafood products and market and processing environments in Iran. Food Control, 34: 630-636.

31. Meloni, D., Galluzo, P., Mureddu, A., Piras, F., Griffiths, M. and Mazzette, R. (2009) Listeria monocytogenes in RTE foods marketed in Italy: Prevalence and automated EcoRI ribotyping of the isolates. Int. J. Food Microbiol., 129: 166-173.

32. Lambertz, S.T., Nilsson, C., Bradenmark, A., Sylven, S., Johansson, A., Jansson, L.M. and Lindblad, M. (2012) Prevalence and level of Listeria monocytogenes in ready-toeat foods in Sweden 2010. Int. J. Food Microbiol., 160(1): 24-31.

33. Gombas, D.E., Chen, Y., Clavero, R.S. and Scott, V.N. (2003) Survey of Listeria monocytogenes in ready-to-eat foods. J. Food Protect., 66: 559-569.

34. Pesavento, G., Ducci, B., Nieri, D., Comodo, N. and Lo Nostro, A. (2010) Prevalence and antibiotic susceptibility of Listeria spp. isolated from raw meat and retail foods. Food Control, 21: 708-713.

35. González, D., Vitas, A.I., Díez-Leturia, M. and García-Jalón, I. (2013) Listeria monocytogenes and readyto-eat seafood in Spain: Study of prevalence and temperatures at retail. Food Microbiol., 36(2): 374-378.

36. Baek, S.Y., Lim, S.Y., Lee, D.H., Min, K.H. and Kim, C.M. (2000) Incidence and characterization of Listeria monocytogenes from domestic and imported foods in Korea. J. Food Protect., 63: 186-189.

37. ICMSF (International Commission on Microbiological Specification of Foods). (1994) Choice of sampling plan and criteria for Listeria monocytogenes. Int. J. Food Microbiol., 22: 89-96.
38. ICMSF (International Commission on Microbiological Specification of Foods) (1996) Establishment of sampling plans for microbiological criteria for foods in international trade including recommendations for control of Listeria monocytogenes, Salmonella enteritidis, Campylobacter and enterohemorrhagic E. coli. Codex Committee on Food Hygiene, 39 $9^{\text {th }}$ Session, 21 to 26 October 1996, Agenda item 11, CX/FH 96/91-16. Codex Alimentarius Commission, Rome.

39. The Commission of the European Communities. (2005) Commission Regulation (EC) No. 2073/2005 on microbiological criteria for foodstuffs. Official J. Eur. Union, L338: 1-26.

40. Van Coillie, E., Werbrouck, H., Heyndrickx, M., Herman, L. and Rijpens, N. (2004) Prevalence and typing of Listeria monocytogenes in ready-to-eat food products on the Belgian market. J. Food Protect., 67: 2480-2487.

41. Dominguez, C., Gomez, I. and Zumalacarregui, J. (2001) Prevalence and contamination levels of Listeria monocytogenes in smoked fish and pâté sold in Spain. J. Food Protect., 64: 2075-2077.

42. Kathariou, S. (2002) L. monocytogenes virulence and pathogenicity, a food safety perspective. J. Food Protect., 65: 1811-1829.

43. Liu, D. (2006) Identification, subtyping and virulence determination of Listeria monocytogenes, an important foodborne pathogen. J. Med. Microbiol., 55: 645-659.

44. Chen, Y. and Knabel, S.J. (2007) Multiplex PCR for simultaneous detection of the genus Listeria, Listeria monocytogenes, and major serotypes and epidemic clones of L. monocytogenes. Appl. Environ. Microbiol., 73: 6299-6304.

45. Autio, T., Lundén, J., Fredriksson-Ahoma, M., Björkroth, J., Sjöberg, A.N. and Korkeala, H. (2002) Similar Listeria monocytogenes pulsotypes detected in several foods originating from different sources. Int. J. Food Microbiol., 77: 83-90.

46. Garrido, V., Vitas, A.I. and García-Jalón, I. (2009) Survey of Listeria monocytogenes in ready-to-eat products: Prevalence by brands and retail establishments for exposure assessment of listeriosis in Northern Spain. Food Control, 20: 986-991.

47. Kramarenko, T., Roasto, M., Meremäe, K., Kuningas, M., Põltsama, P. and Elias, T. (2013) Listeria monocytogenes prevalence and serotype diversity in various foods. Food Control, 30: 24-29.

48. Siriken, B., Ayaz, N.D. and Erol, I. (2013) Prevalence and serotype distribution of Listeria monocytogenes in salted anchovy, raw anchovy, and raw mussel using IMS-based cultivation technique and PCR. J. Aquat. Food Prod. Technol., 22: 77-82.

49. Wang, X.M., Lü, X.F., Yin, L., Liu, H.F., Zhang, W.J., Si, W., Yu, S.Y, Shao, M.L. and Liu, S.G. (2013) Occurrence and antimicrobial susceptibility of Listeria monocytogenes isolates from retail raw foods. Food Control, 32: 153-158.

50. Jamali, H. and Thong, K.L. (2014) Genotypic characterization and antimicrobial resistance of Listeria monocytogenes from ready-to-eat foods. Food Control, 44: 1-6. 